\title{
Analytical methods applied for the characterization and the determination of bioactive compounds in coffee
}

\author{
Magdalena Jeszka-Skowron • Agnieszka Zgoła-Grześkowiak • \\ Tomasz Grześkowiak
}

Received: 8 July 2014 / Revised: 4 October 2014 / Accepted: 5 October 2014 / Published online: 16 October 2014

(C) The Author(s) 2014. This article is published with open access at Springerlink.com

\begin{abstract}
Coffee, the one of the most popular beverages in the world, contains many bioactive compounds especially caffeine-the natural stimulant and chlorogenic acids with antioxidative properties. Other chemicals such as diterpenes may influence human serum lipids and protect from the risk of some types of cancer. All these compounds are widely determined in Coffea arabica and robusta green and roasted coffee beans, coffee brews and instant coffees to increase food quality standards. The most important analytical methods are reviewed, including these using high-performance liquid chromatography, ultraviolet spectrophotometry and voltammetry techniques, that have been applied to quantify the major bioactive compounds of coffee samples: phenols-inter alia chlorogenic acids and derivatives; methylxanthines-caffeine; trigonelline; nicotinic acid; diterpenes; and short-chain carboxylic acids. Usage of hyphenated techniques such as liquid chromatography-mass spectrometry and gas chromatography-mass spectrometry for identification and determination of coffee constituents is also presented.
\end{abstract}

Keywords Coffee $\cdot$ Chlorogenic acids $\cdot$ Caffeine · Trigonelline $\cdot$ Nicotinic acid $\cdot$ Diterpenes

\section{Introduction}

Coffee is prepared from the roasted seeds (beans) derived from a bush of the genus Coffea. This drink was first

M. Jeszka-Skowron $(\bowtie) \cdot$ A. Zgoła-Grześkowiak ·

T. Grześkowiak

Institute of Chemistry and Technical Electrochemistry, Poznan

University of Technology, 60-965 Poznań, Poland

e-mail: magdalena.jeszka-skowron@ put.poznan.pl prepared in Ethiopia and then in fifteenth century in Yemeni Sufi monasteries, from where it disseminated into the rest of the Middle East and northern Africa. The intense trade of the Venetian ships with the Middle East opened the doors of Europe to coffee, from where it was subsequently introduced to America [1].

Among about 500 species of coffee, only Coffea arabica and Coffea canephora (robusta) have significant position in production and export. These two species differ by appearance and origin and lastly but most importantly by its quality and flavor. Mild Arabica comes from upland and mountain areas of East Africa (Ethiopia) and Robusta from lowland of Central and West Africa.

The coffee consumption in emerging countries noted $21 \%$ rise between 2009 and 2012. This corresponds to substantial increase in world coffee production which rose from 133.5 million (60-kg bags) in 2010/2011 crop year to 144.6 million in 2012/2013 [2]. There are numerous coffee producers, but Brazil and Vietnam reached the considerable production of coffee with 32.4 and $17.9 \%$ share, respectively [3]. Among the most significant Brazilian coffee cultivars, Coffea arabica cv. Mundo Novo, C. arabica cv. Catua1 Vermelho, C. arabica cv. Bourbon and Coffea canephora cv. Conillon (Robusta) are the most popular blends around the world.

Traditionally, it was said that drinking coffee, especially in high amount, caused liver diseases, and therefore, its consumption should be low. But nowadays, the phytochemistry of coffee is known with about 1,000 described phytochemicals. For that reason, in last few decades biological effect of coffee brew on human organism has been widely analyzed and this beverage was named as functional food [4]. Thus, drinking coffee-in appropriate amount-has impact on the cardiovascular system and on the metabolism of carbohydrates and lipids. Opposing to previous 
beliefs, the various forms of arterial cardiovascular disease, arrhythmia or heart insufficiency, seem to be unaffected by coffee intake. Coffee reduces the incidence of cancer, diabetes and liver disease, protects against Parkinson's disease and even reduces mortality risk $[5,6]$.

The most important bioactive compounds of coffee include the following: phenolic compounds (such as chlorogenic acids and derivatives), methylxanthines (caffeine, theophylline and theobromine), diterpenes, (including cafestol and kahweol), nicotinic acid (vitamin $\mathrm{B}_{3}$ ) and its precursor trigonelline, magnesium and potassium [7]. This variability of the coffee chemical constituents should be determined using sensitive, precise and accurate analytical methods to examine the quality, aroma and properties of green and roasted coffee beans, instant coffees and coffee brew.

The traditional sample pre-treatment techniques used in food analysis are liquid-liquid extraction (LLE) and solid phase extraction (SPE) [8]. However, many other techniques are also used including drop-to-drop microextraction [9] or extraction using supercritical carbon dioxide [10]. The processed samples are then analyzed with the use of the advanced separation techniques, such as capillary electrophoresis (CE), high-performance liquid chromatography (HPLC) and ultra-high-pressure liquid chromatography (UHPLC) gas chromatography (GC) as well as with hyphenated techniques using mass spectrometry detection.

The aim of the review is to present and compare the analytical methods that have been applied to characterize and quantify the important bioactive compounds of coffee samples: phenols (chlorogenic acids and derivatives), methylxanthines (mainly caffeine), trigonelline, nicotinic acid, diterpenes and short-chain carboxylic acids.

\section{Determination of phenolic compounds}

Phenolic acids and lactones

The main groups of phenolics in coffee bean are chlorogenic acids (CGA) presented in Fig. 1 according to their chemical identity, number and position of acyl residues. This group of compounds includes the following: caffeoylquinic acids (CQA), with 3 isomers (3-, 4- and 5-CQA), dicaffeoylquinic acids (diCQA) with 3 isomers (3,4-diCQA; 3,5-diCQA; 4,5-diCQA), feruloylquinic acids (FQA) with 3 isomers (3-, 4- and 5-FQA), p-coumaroylquinic acids (pCoQA) with 3 isomers (3-, 4- and 5pCoQA) and mixed diesters of caffeoylferuloylquinic acids (CFQA) [11, 12]. The first three compounds account for about $83 \%$ of the total CGA in green beans [13]. Chlorogenic acids act as antioxidants [14] and showed hepatoprotective, hypoglycemic and antiviral activities.
The group of CGA is present in the coffee beans in high concentration and determines the quality of coffee and its flavor [15]. However, the total CGA content of green coffee beans may vary not only according to genetics-species but also to the degree of maturation, agricultural practices, climate and soil [16, 17]. For example CGA content found in different coffee species of wild Coffea genetic resources varies between 0.61 and $1.05 \%$ for Coffea sp. Bakossito and 11.1-12.7 \% dry basis for Coffea sp. N' koumbala [18].

To analyze these compounds in green coffee beans, the material must be crushed and frozen. It can be extracted with methanol/water mixture, filtered and analyzed directly using HPLC according to the official norm [19]. Many other procedures include sample clean-up. These include the following:

1. overnight extraction using $70 \%(\mathrm{v} / \mathrm{v})$ methanol/water mixture at $4{ }^{\circ} \mathrm{C}$ and then (after evaporation of methanol): LLE of water solution with different organic solvents [20] or filtration through a $\mathrm{C}_{18}$ cartridge [21] or extraction on activated carbon [22] or treatment by Carrez reagents [23];

2. overnight extraction using $70 \%(\mathrm{v} / \mathrm{v})$ methanol/water mixture at $4{ }^{\circ} \mathrm{C}$ and then (without evaporation of methanol) treatment by Carrez reagents [15, 24];

3. $15 \mathrm{~min}$ extraction with methanol/water/acetic acid (30:67.5:2.5, v/v/v) with ascorbic acid $(2 \mathrm{~g} / \mathrm{L})$ in an ultrasonic bath [25].

Furthermore, microwave-assisted extraction [26] and extraction using boiling water under elevated pressure [27] have been successfully developed. These two methods are advantageous because some of Carrez reagent products could react with CGA in the HPLC phase [28]. Table 1 shows the different methods of extraction process used for the determination of CGA.

The determination of wide range of phenolic compounds in green coffee beans in one analysis can be problematic. Therefore, the LC-MS system should be applied to improve selectivity. Fourteen CGA compounds-3-CQA, 4-CQA, 5-CQA, 3-FQA, 4-FQA, 5-FQA, 3-p-CoQA, 4-p-CoQA, 5-p-CoQA, 3,4-diCQA, 3,5-diCQA, 4,5-diCQA, 3,4-diFQA and 3,4-di-p-CoQA - and six CFQA isomers were identified in green $C$. arabica and $C$. canephora samples using ${\mathrm{LC}-M S^{\mathrm{n}}}$ system [29]. No lactones of chlorogenic acids were determined in green coffee samples, with the exception of a small amount of 3-FQL present in Mundo Novo cultivar. Also three caffeoylquinic acids CQA, three FQA, one pCoQA, three diCQA, three FCQA, four pCoCQA, three diFQA, six DCQA and six DFQA were found [25]. Moreover, three trans-cinnamic acids (caffeic, ferulic and dimethoxycinnamic), six cinnamoyl-amino acid conjugates (caffeoyl$N$-tyrosine, p-coumaroyl- $N$-tyrosine, caffeoyl- $N$-tryptophan, 
Fig. 1 Chemical structures of chlorogenic acids and derivatives, caffeic acid, ferulic and $p$-coumaric acids, trigonelline, nicotinic acid, theobromine, theophylline and caffeine determined in coffee<smiles>O=C(O)C1C(O)C2C(O)C3C(O)C(O)C2CC1C3O</smiles>

quinic acid

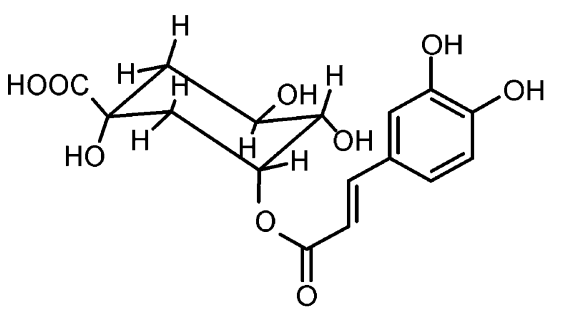

3-caffeoylquinic acid<smiles>O=C(O)C1C(O)C2C3CC1C(O)C2C(C(=O)O)C3O</smiles>

5-caffeoylquinic acid

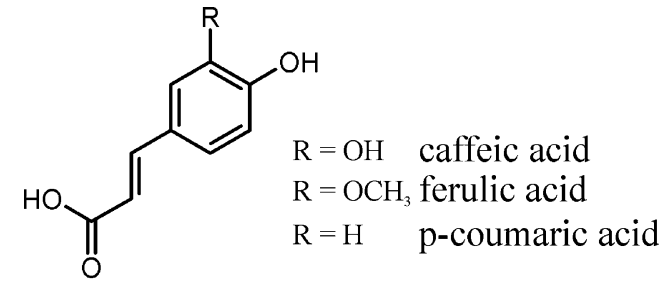

cinnamic acid

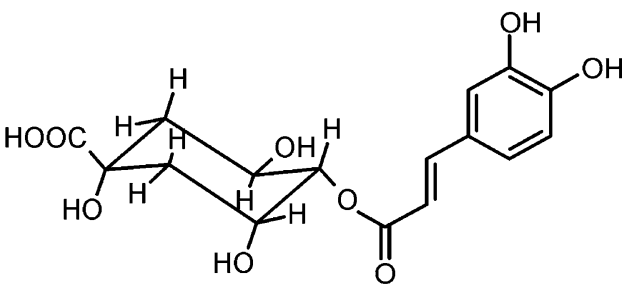
4-caffeoylquinic acid<smiles>C[n+]1cccc(C(=O)[O-])c1</smiles>

trigonelline<smiles>O=C(O)c1cccnc1</smiles>

nicotinic acid<smiles>Cn1cnc2c1c(=O)[nH]c(=O)n2C</smiles>

theobromine<smiles>Cn1c(=O)c2[nH]cnc2n(C)c1=O</smiles>

theophylline<smiles>Cn1c(=O)c2c(ncn2C)n(C)c1=O</smiles>

caffeine p-coumaroyl- $N$-tryptophan, feruloyl- $N$-tryptophan, caffeoyl$\mathrm{N}$-phenylalanine) and three cinnamoyl glycosides (caffeoylhexose, dicaffeoylhexose and dimethoxycinnamoylhexose) were also determined in the coffee bean samples [25]. The highest level of phenolic compounds was determined in Robusta green coffee beans. Likewise, the liquid chromatography multi-stage spectrometric technique has been used to determine 3,4,5-triacylchlorogenic acids in coffee beans [29]. Kuhnert et al. [30] analyzed aqueous methanolic extracts by LC-ESI-TOF-MS. The procedure was successfully applied for analysis of 38 green bean coffee samples, which vary in terms of coffee variety and processing conditions.

CGA can also be analyzed using micellar electrokinetic chromatography (MEKC). In the proposed method, caffeoylquinic (chlorogenic) acid, caffeic and ferulic acid were determined in green coffee. A silica capillary with a solvent system that utilizes phosphate buffer and methanol was applied and the analysis lasted for only $9 \min$ [31].

Besides the techniques allowing for separation of components, UV spectrometry analyses of CGAs were also developed [26, 32]. These methods are not so selective like the LC-MS procedures. However, they can be used for fast scanning giving basic information.

Chlorogenic acids of coffee brew are responsible for aroma and astringency. During roasting, a part of CGA is isomerized, a part is transformed into quinolactones due to dehydration and formation of an intramolecular bond, and a part is hydrolyzed and degraded into low molecular weight compounds or even reduced $[12,13,16]$. It depends on parameters of roasting process and coffee preparing [33-35].

Therefore, there are many analytical methods to identify and quantify these compounds in different coffee brews. 


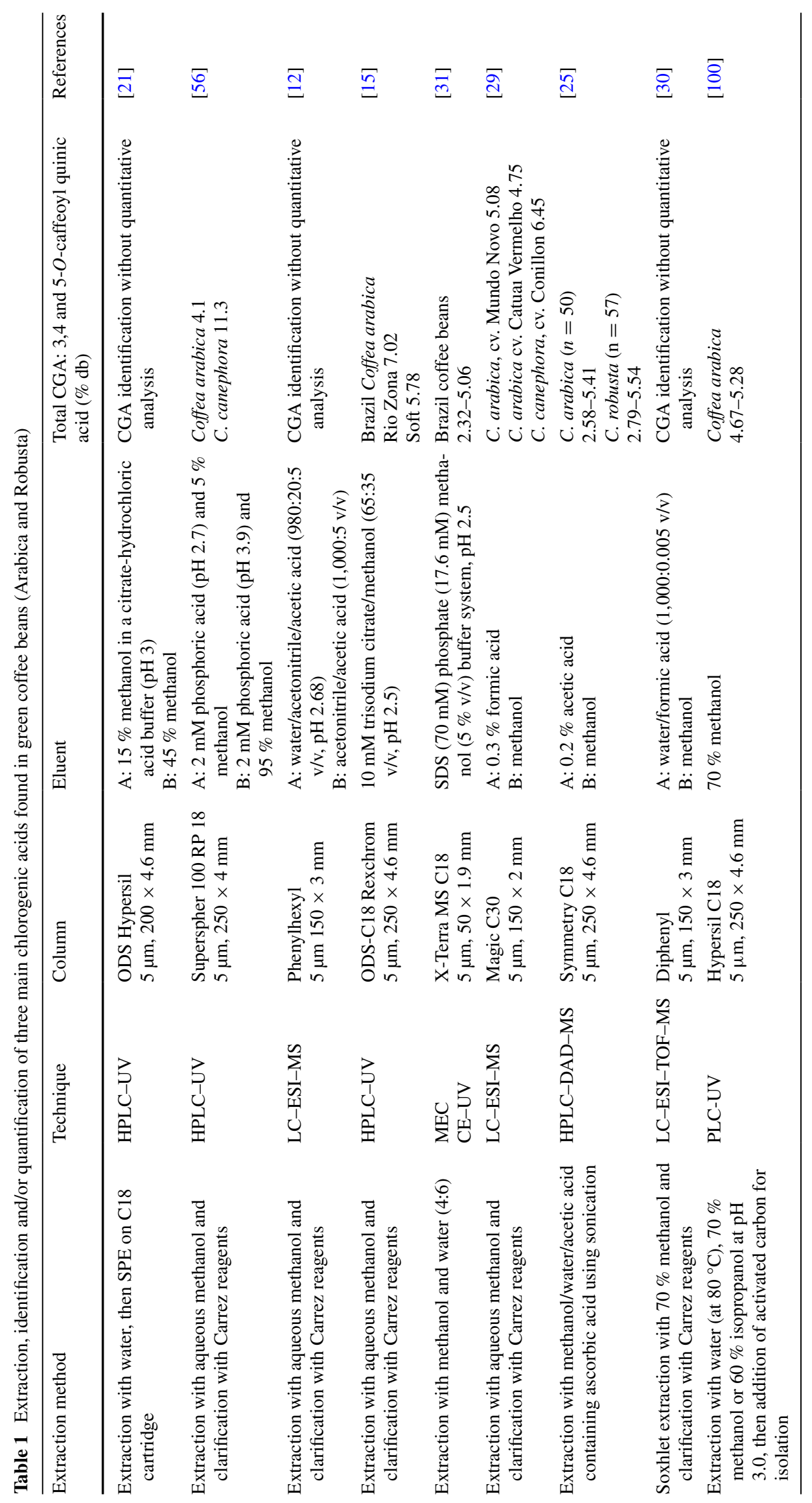


Most of them use chromatographic techniques (Table 2). Perrone et al. [29] found, apart from nineteen previously identified CGA and chlorogenic acid lactones, also such compounds as: 1-feruloylquinic acid, 1-feruloylquinic lactone and 3,4-diferuloylquinic acid in $C$. arabica and $C$. canephora, 3- and 4-p-coumaroylquinic lactones in $C$. canephora and 3,4-di-p-coumaroylquinic acid in C. Arabica.

The other procedure enabled simultaneous determination of CGA and derivatives using HPLC-DAD-MS ${ }^{n}$. Seventeen chlorogenic acids, five chlorogenic acid lactones, two cinnamoyl-amino acid conjugates and two free cinnamic acids were analyzed in coffee brews [36]. Although CFQA isomers were previously found in roasted coffee $[29,37]$, it was the first study where each CFQA isomer was identified and quantified separately in roasted coffee. Latest research using $\mathrm{LC}-\mathrm{MS}^{\mathrm{n}}$ system showed that also cinnamoylshikimate esters can be found in roasted coffee [38]. Jaiswal et al. were able to discriminate between the individual types of cinnamoylshikimate esters and chlorogenic acid lactones, and these compounds were assigned on the basis of $\mathrm{MS}^{3}$ patterns of fragmentation [38].

Kaiser et al. [39] used high-speed countercurrent chromatography to isolate milligram amounts of lactones. They found the new structures of 3-O-caffeoyl- $\gamma$-quinide, 4- $O$-caffeoyl-muco- $\gamma$-quinide and 5-O-caffeoyl-epi- $\delta$ quinide, and they confirmed them by 1D and 2D NMR spectroscopy including ${ }^{13} \mathrm{C}$ NMR data. It was shown that complex quinide mixtures could be separated by UHPLC in shorter time with the same or even better resolution compared with common HPLC analysis.

Apart from chromatographic techniques more widely used become electroanalytical methods, especially voltammetry due to its simplicity, fast response, low cost and satisfactory sensitivity have been established. The most popular techniques differential pulse voltammetry, square-wave voltammetry and adsorptive stripping voltammetry were successfully applied for analysis of chlorogenic acid in coffee brew [40-45]. These methods are based on glassy carbon electrode [45] or carbon paste electrode [41, 42] or Au electrode [43], or boron-doped diamond (BDD) electrode [44] with different modifiers such as multi-walled carbon nanotubes [45] or ionic liquid containing iridium nanoparticles and polyphenol oxidase [42], or molecular imprinted polymer [43]. However, it must be taken into consideration that these electroanalytical methods, although inexpensive, can only be used for basic analyses. Selective determination of a number of particular CQAs (contrary to LC-MS methods) is not possible.

Isoflavones: daidzein, genistein and formononetin

Apart from phenolic acids and lactones and derivatives, coffee fruits and brew contain other important bioactive phenolics such as isoflavones, lignans, tannins and anthocyanins. Isoflavones such as daidzein, genistein or formononetin and lignans such as secoisolariciresinol, matairesinol, pinoresinol or lariciresinol belong to the group of phytoestrogens which are used to protect from hypercholesterolemia, carcinogenesis and osteoporosis, and they relieve menopausal symptoms [46].

Isoflavones and other phytoestrogens of coffee samples are usually determined with the use of HPLC [47] or gas chromatography-mass spectrometry (GC-MS) [48, 49] or using automatic SPE and LC-MS/MS [50]. To free the aglicones of isoflavones from glycosides or glycoside esters and quantify them, acid hydrolysis [47] or enzymatic procedure [51] was applied. Thompson et al. [49] analyzed the commercial coffee samples for isoflavones (genistein, daidzein, glycitein, formononetin), lignans (secoisolariciresinol, matairesinol, pinoresinol, lariciresinol) and coumestan (coumestrol) with the use of GC-MS. Instant coffee contain 1,000-fold higher level of phytoestrogens than coffee brew [52].

\section{Determination of caffeine and other methylxanthines}

Caffeine (1,3,7-trimethylxanthine) is the major alkaloid present in green coffee beans which also can be found in considerable concentration in roasted coffee [36, 53, 54]. Because of its stimulating effect on the central nervous system, it is also the most widely known constituent of coffee [55]. However, it is not associated by most people with taste of coffee brew although it contributes to the brew bitterness $[15,56]$.

Concentration of caffeine in coffee beans depends mainly on its species. Green beans of Coffea arabica contain between 0.7 and $1.6 \%$ caffeine and of Coffea canephora between 1.5 and $4.0 \%$ [54, 56]. Two other methylxanthines are also reported in coffee brews, i.e., theobromine (3,7-dimethylxanthine) and theophylline (1,3-dimethylxanthine). However, these methylxanthines can be found in coffee in considerably lower amounts than caffeine and are rarely analyzed [36].

Caffeine is determined in coffee samples usually with the use of HPLC. Sample preparation before this analysis is usually very simple and contains only filtration and dilution steps $[54,57,58]$. Some methods include clarification with Carrez reagents [15, 36, 53] or with lead acetate [59]. Alternatively, sample can be cleaned up by water extraction of powdered coffee beans mixed with magnesium oxide [56] or using solid phase extraction $[27,60]$. The samples prepared according to one of these procedures were analyzed in a reverse phase elution mode with octadecylsilicapacked column. Caffeine was detected with the ultraviolet absorbance detector at 270-280 nm [11, 15, 27, 36, 53, 54, $56-58,60]$. Alternatively, HPLC with mass spectrometry 


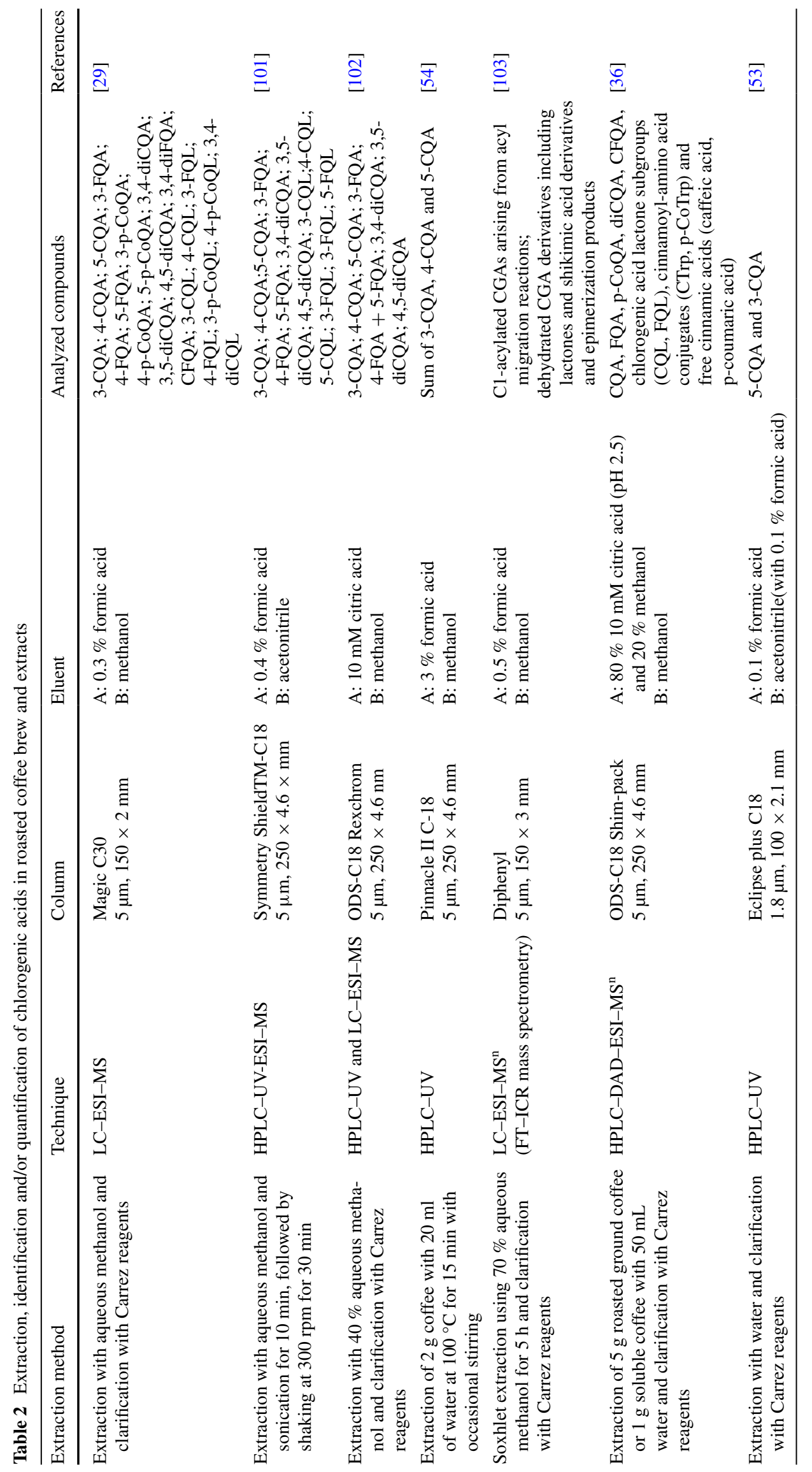


was used for determination of caffeine [59] or theobromine and theophylline [36].

Other chromatographic techniques are rarely used for the determination of caffeine in coffee samples. Examples include GC-MS [9] and MEKC with ultraviolet absorbance detection [61]. Relatively fast and simple sample preparation was used in both these studies. Drop-to-drop microextraction from water sample to chloroform was used before GC analysis [9]. Chloroform extraction from beans, evaporation and reconstitution into water was used before MEKC analysis [61].

Non-chromatographic methods applied for the determination of caffeine included use of several techniques. Direct analysis in real-time ionization (DART) - high-resolution mass spectrometry - was used as a fast and selective technique. The coffee brew sample for this analysis can be placed directly in the DART ion source, and time of flight mass spectrometer enables high-resolution measurement of obtained mass spectra, i.e., high selectivity. Variations of signal due to matrix effect and ion source instability were compensated by addition of isotopically labeled caffeine standard [62].

Caffeine was also determined with the use of Fourier transform infrared (FTIR) spectroscopy in combination with attenuated total reflectance (ATR) techniques. In the proposed method, a chloroform extract of caffeine from coffee brew was evaporated on a zinc selenide crystal. Caffeine signal was monitored at $1,655 \mathrm{~cm}^{-1}$ [63]. The method is faster and relatively simple. However, combination of ATR with FTIR is not a popular analytical technique. Moreover, only one compound was determined in the presented procedure.

Other methods used for the determination of caffeine in coffee include UV spectrometry [54, 64, 65], voltammetry [44, 66], gravimetric analysis [54] and paper substrate phosphorescence [67]. As direct measurement of caffeine UV absorbance in water extract of coffee is impossible because of high matrix effects, Balay et al. [64] proposed usage of dichloromethane for its extraction before UV measurement. Hečimovič et al. [54] used two different procedures for sample clean-up before UV analysis. In the first one, lead acetate was used for clarification, and in the second one extraction with benzene and back extraction to $5 \mathrm{~N} \mathrm{H}_{2} \mathrm{SO}_{4}$ were applied. The results obtained with these methods were, however, considerably lower than with the reference HPLC method [54]. On the other hand, the use of a gravimetric method proposed in the same paper resulted in higher agreement with the HPLC method. In this procedure, coffee brew was clarified with lead acetate, extracted with chloroform and washed with $\mathrm{KOH}$ solution. Caffeine was determined gravimetrically from evaporated chloroform extract [54]. Another approach to UV analysis was proposed by Salinas-Vargas and Cañizares-Macías who used complicated sample preparation before the measurement [65]. The coffee samples were clarified with the Carrez reagents and then cleaned up using on-line SPE procedure with octadecylsilica cartridge. Satisfactory recoveries were obtained in different samples of green and roasted coffee beans.

Caffeine can also be determined successfully with voltammetric methods. Yardim et al. [44] used a BDD electrode for simultaneous determination of caffeine and chlorogenic acid in coffee. As fouling occurred at the BDD electrode, anodic cleaning in $0.5 \mathrm{M} \mathrm{H}_{2} \mathrm{SO}_{4}$ was used. It enabled successful determination of caffeine and chlorogenic acid with limits of detection 0.55 and $1.26 \mu \mathrm{M}$, respectively [44]. Aklilu et al. [66] used a carbon paste electrode for determination of caffeine. Problems with high background in its determination led to high limit of detection which was solved by modification of the electrode. The 1,4-benzoquinone modified carbon paste electrode enabled indirect voltammetric determination of caffeine in coffee extracts with limit of detection $0.3 \mu \mathrm{M}$ [66]. Mersal used a pseudo-carbon paste electrode (made from $65 \%$ graphite powder and $35 \%$ paraffin) in both cyclic voltammetry and square-wave voltammetric measurements of caffeine [68]. Among these two techniques, square-wave voltammetric was found better for the determination of caffeine as it led to a well-formed oxidation peak. The presented voltammetric methods are fast and inexpensive. However, not many compounds can be determined using these procedures.

Finally, an example of a rarely used analytical technique must be mentioned. The paper substrate room temperature phosphorescence was used for analysis of caffeine, theobromine and theophylline in selected products. In the developed method, a sample was introduced onto the filter paper strip together with $\mathrm{KI} / \mathrm{CH}_{3} \mathrm{Na}$ solution used for signal enhancement. Phosphorescence of the sample spot was measured with a fluorescence spectrometer. The limits of detection were from 0.8 to $1.8 \mathrm{ng}$ per spot. However, the method was not selective, as each of the three methylxanthines had analytical signal at the same region of wavelengths. Therefore, caffeine was determined as main constituent in coffee and tea, theobromine in chocolate and theophylline in tablets containing this active pharmaceutical ingredient [67].

\section{Determination of trigonelline and nicotinic acid}

Trigonelline ( $N$-methyl nicotinic acid) (Fig. 1) is a nitrogenous compound, a pyridine alkaloid that is derived from the methylation of the nitrogen atom of nicotinic acid (niacin). Trigonelline is the second main alkaloid found in green coffee beans. During the roasting process, trigonelline suffers severe thermal degradation generating a series 
of volatile compounds responsible for flavor formation and aroma production and it is used as roasting-level discriminator in both Arabica and Robusta coffees [56, 59, 69]. The compounds, such as pyridine and pyrrole derivatives, nicotinic acid, methyl ester of nicotinic acid and above 20 different compounds, are formed [70, 71]. Trigonelline is also degraded by decarboxylation generating the $N$-methylpyridinium cation, the inductor of enzyme systems involved in detoxification of xenobiotics [72], activator of the Nrf2/ ARE pathway, inducing cellular defense mechanisms [73, 74] and novel phytoestrogen [75].

HPLC is the main technique used for the determination of trigonelline and nicotinic acid in coffee beans. Several examples of these methods are presented in Table 3. Nevertheless, gas chromatography was also used for analysis of trigonelline [70].

The contents of trigonelline and nicotinic acid in coffee brews may be highly influenced by coffee species, variety, geographical origin and roasting conditions [56, 58]. Fast LC-MS method (6 min of analysis) simultaneously determined caffeine, trigonelline, nicotinic acid and sucrose [59]. This method showed appropriate recoveries and repeat abilities (RSD $<5 \%$ ) for all analytes in the matrix. The limit of detection (LOD), calculated on the basis of signal-to-noise ratios of $3: 1$, was $11.9,36.4,18.5$ and $5.0 \mathrm{ng} \mathrm{mL}^{-1}$ for caffeine, trigonelline, nicotinic acid and sucrose, respectively. The content of trigonelline in coffee beans of Arabica was slightly higher than in Robusta ( 1.03 vs. $0.9 \%$ on the dry basis). Nicotinic acid in extracts of regular commercial ground roasted coffee, decaffeinated and instant coffees was determined. There was no difference in its level between these beverages [59]. Similar results were found by Liu et al. [76] who developed the separation of trigonelline, nicotinic acid and caffeine by HPLC using two chromatographic columns in series.

Quantitation of trigonelline and $N$-methylpyridinium in roasted coffee was developed using a HILIC-LC-MS/MS method [77]. This investigation showed that the formation and degradation of these coffee bioactive compounds had influence on color and aroma.

Besides chromatographic techniques, the proton nuclear magnetic resonance technique ( ${ }^{1} \mathrm{H}$ NMR) was applied [7880]. ${ }^{1} \mathrm{H}$ NMR spectrum at the $7.5-10.0 \mathrm{ppm}$ range for the quantitative and simultaneous determination of caffeine, formic acid, trigonelline and 5-(hydroxymethyl)-2-furaldehyde was obtained [80]. The time of analysis was $20 \mathrm{~min}$ with no need of any previous derivatization or treatment.

\section{Determination of diterpenes}

Cafestol and kahweol as anti-nutritional factors are unique chemicals to coffee beans and brews. These compounds and coffee drinking are positively correlated with higher level of serum cholesterol lipids, especially in patients with hyperlipidemia [81, 82]. Latest research showed that they reduce the risk of colorectal cancer [83].

Analysis of diterpenes can be easily performed with the use of GC-FID. Soxhlet extraction can be used to extract these compounds from the beans [84]. Further treatment includes saponification which is also used in preparation of coffee extract samples, and then, the samples are silylated $[84,85]$. Chartier et al. [86] proposed a simplified procedure with automatic transesterification of the esters of diterpenes in a flow reactor. Diterpenes from the reactor were further cleaned up and injected into GC-FID without silylation.

HPLC is the alternative technique which can be used for the determination of diterpenes. Gross et al. used SPE and saponification for coffee sample preparation and analyzed diterpenes with HPLC-UV at $230 \mathrm{~nm}$ for cafestol and $290 \mathrm{~nm}$ for kahweol [87]. Sridevi et al. [88] used a 6-h-long Soxhlet extraction for powdered coffee beans. The free diterpenes from unsaponified extracts or brews were determined with HPLV-UV at the above-mentioned wavelengths. On the other hand, Araujo and Sandi developed green chemistry method of extraction using supercritical carbon dioxide before sample saponification and analysis with the use of HPLC-UV at $220 \mathrm{~nm}$ [10]. Use of mass spectrometry for analyte detection is another option possible in HPLC analysis, which gives additional selectivity. Oigman et al. [89] analyzed kahweol and cafestol using LC-HRMS after microwave methanolysis of coffee samples. Latest research showed that for the determination of diterpenes in green coffee samples the 10-min-long microwave-assisted extraction was considerably less time consuming than the 4-h-long traditional Soxhlet extraction, while amount of extracted diterpenes was similar [90]. Other modern extraction method-used for spent coffee grounds-was supercritical fluid extraction. This optimized extraction method led to diterpenes concentrations from 2 to 4 times higher than using Soxhlet apparatus [91]. Scharnhop and Winterhalter employed high-speed countercurrent chromatography for the isolation and purification of different diterpenes (i.e., kahweol, cafestol, 16-O-methylkahweol, 16-O-methylcafestol, dehydrokahweol, and dehydrocafestol) from Coffea arabica and Coffea canephora var. robusta [92]. The solvent systems consisted of hexane-ethyl acetate-ethanol-water mixtures. Identity and purity of the isolated compounds were confirmed by HPLC-DAD and LC-MS ${ }^{\mathrm{n}}$ as well as NMR measurements. Another NMR method developed for the analysis of green coffee beans required the 4-h-long Soxhlet extraction with pentane. After drying and evaporation of pentane, obtained coffee oil was subjected to NMR analysis which enabled clear discrimination between Arabica and Robusta [93]. 


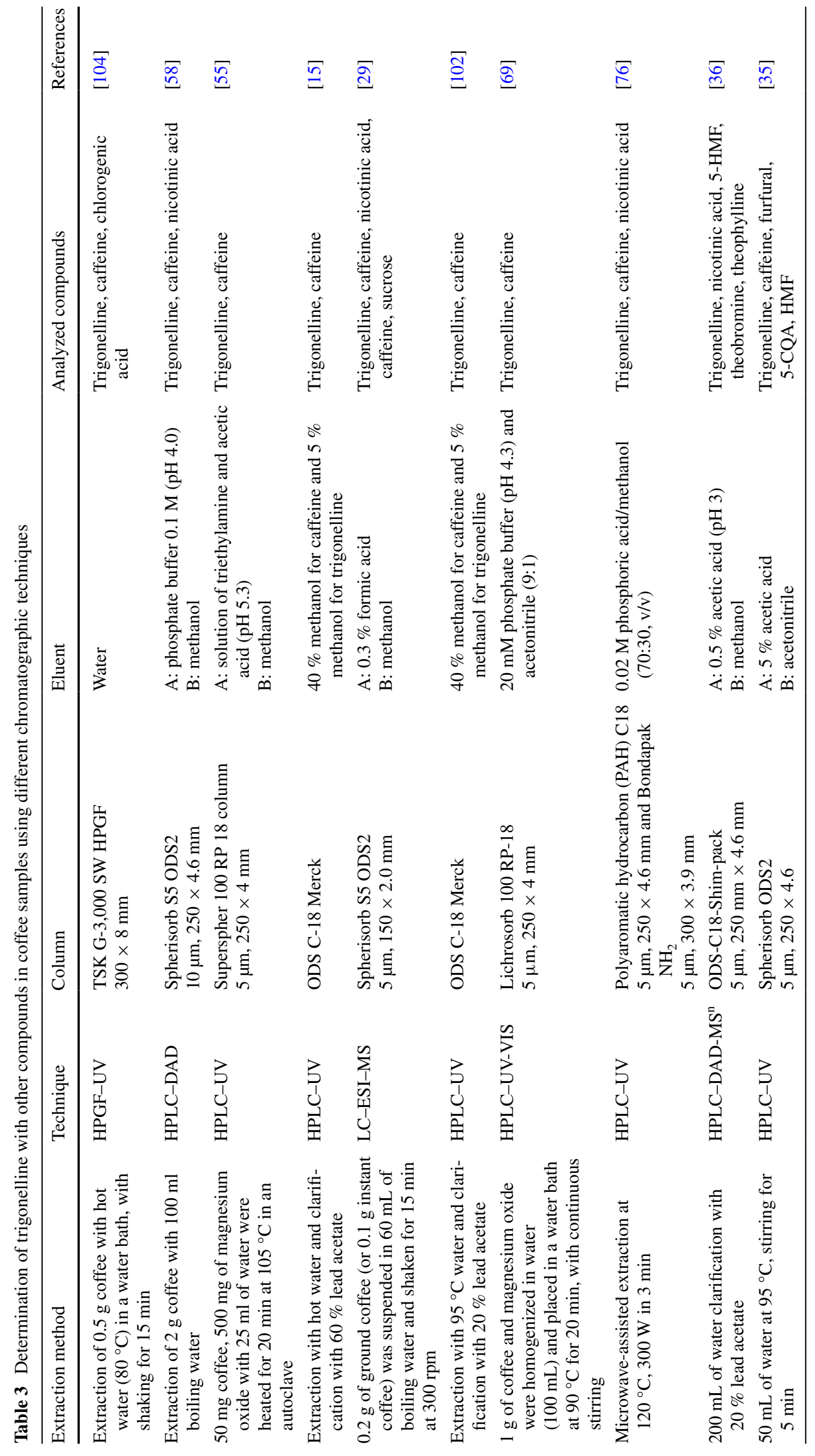


Coffee beans contain $0.15-0.37 \%$ (Robusta) and $0.27-$ $0.67 \%$ (Arabica) d.m. of cafestol. Similarly kahweol levels are $0.1 \%$ d.m. and $0.11-0.35 \%$ d.m. in Robusta and Arabica beans, respectively [94]. Cafestol and kahweol levels in brews such as espresso, Turkish-style and French press coffee were significantly higher than in filtered or instant coffee [87]. Similarly higher roasting temperatures and prolonged roasting times had influence on diterpenes profiles in roasted beans $[88,95]$. Cafestol and kahweol were degraded to dehydrocafestol and dehydrokahweol after 8 min of roasting process [95].

\section{Determination of short-chain carboxylic acids and inorganic ions}

Simple aliphatic carboxylic acids and inorganic acids are rarely analyzed in coffee although their acidity contributes to sourness of coffee brew and therefore to its taste. In fact, a major taste of high-quality Arabica coffee is sourness [60, 96]. Amount of acids in green coffee beans changes during their maturation. In the mature beans, mainly citric and malic acids were found at about 1.5 and $0.4 \%$, respectively. Among inorganic ions, phosphates dominated. They were found at concentration $0.1 \%$ [97]. The roasting process, however, leads to changes in amounts of simple aliphatic carboxylic acids. Concentrations of citric and malic acids slightly decrease. In the same time, considerable increase in formic, acetic, glycolic and lactic acids can be observed, while phosphates are little affected by the roasting process [98]. Therefore, analysis of these compounds is so important.

The aliphatic carboxylic acids and phosphates can be analyzed using different analytical techniques. Verardo et al. [98] used gas chromatography with mass spectrometric detection. The acids were derivatized before analysis with diazobutane (used for low molecular weight (C1-C3) acids) or with diazomethane (used for other acids). The procedure was successfully applied for analysis of different coffee types and for analysis of changes in coffee caused by the roasting process [98]. Bähre and Maier also applied gas chromatography with mass spectrometric detection for analysis of carboxylic acids in coffee [99]. Samples were cleaned up before analysis using electrophoresis, and acids were derivatized with trimethylchlorosilane. A number of acids were identified including some that were not reported in coffee samples before [99].

Electrophoretic techniques can be used not only for sample clean-up. Capillary electrophoresis was successfully applied for the determination of short-chain organic acids in coffee. No derivatization was needed, and acids were analyzed using UV detector at $200 \mathrm{~nm}$. The developed method was applied for determination of almost twenty different acids [96].
Simple aliphatic carboxylic acids were also analyzed using HPLC. Different columns and elution modes were used. Rogers et al. [97] applied high-performance anion exchange chromatography coupled to pulsed electrochemical detection. A number of coffee constituent were analyzed using different chromatographic columns. Carboxylic acids and inorganic anions were determined on an AS11 column (containing polymeric resin with alkanol quaternary ammonium functional groups) in a gradient of sodium hydroxide solution [97]. Rodrigues et al. [60] analyzed short-chain organic acids using HPLC in a reversed phase elution mode. Samples were cleaned up using a strong anion exchange solid phase extraction column. Then, they were analyzed on an octadecylsilica column using $25 \mathrm{mM} \mathrm{pH} 2.4$ phosphate buffer with $1 \%$ methanol for elution. Signal was monitored using UV detection at $210 \mathrm{~nm}$. The developed method was applied for the determination of acids in a number of coffee samples from 10 different geographical origins [60].

\section{Conclusions}

Chlorogenic acids and derivatives, caffeine and trigonelline seem to be the most popular compounds determined in green coffee beans, coffee brews and instant coffees. For standardized analysis of these compounds, HPLCUV technique appears to be the most appropriate although faster separations are achieved using UHPLC. The use of the LC-MS techniques enables to measure entire range of chlorogenic acids and derivatives and can also be used for identification of unknown constituents.

\section{Conflict of interest None.}

Compliance with Ethics Requirements This article does not contain any studies with human or animal subjects.

Open Access This article is distributed under the terms of the Creative Commons Attribution License which permits any use, distribution, and reproduction in any medium, provided the original author(s) and the source are credited.

\section{References}

1. Wolf A, Bray GA, Popkin BM (2008) A short history of beverages and how our body treats them. Obes Rev 9:151-164

2. Agritrade. Informed Analysis, Expert Opinions. Executive Brief. (2013) Technical Centre for Agricultural and Rural Cooperation. Wageningen, The Netherlands

3. International Coffee Organization (2013) Annual Review 2011/12. London, United Kingdom

4. Esquivel P, Jiménez VM (2012) Functional properties of coffee and coffee by-products. Food Res Int 46:488-495

5. Bhupathiraju SN, Pan A, Malik VS, Manson JE, Willett WC, van Dam RM, Hu FB (2013) Caffeinated and caffeine-free beverages and risk of type 2 diabetes. Am J Clin Nutr 97:155-166 
6. Cano-Marquina A, Tarín JJ, Cano A (2013) The impact of coffee on health. Maturitas 75:7-21

7. Gómez-Ruiz JA, Leake DS, Ames JM (2007) In vitro antioxidant activity of coffee compounds and their metabolites. J Agric Food Chem 55:6962-6969

8. Motilva M-J, Serra A, Macià A (2013) Analysis of food polyphenols by ultra high-performance liquid chromatography coupled to mass spectrometry: an overview. J Chromatogr A 1292:66-82

9. Shrivas K, Wu HF (2007) Rapid determination of caffeine in one drop of beverages and foods using drop-to-drop solvent microextraction with gas chromatography/mass spectrometry. $\mathbf{J}$ Chromatogr A 1170:9-14

10. Araujo JMA, Sandi D (2006) Extraction of coffee diterpenes and coffee oil using supercritical carbon dioxide. Food Chem 101:1087-1094

11. Alonso-Salces RM, Guillou C, Berrueta LA (2009) Liquid chromatography coupled with ultraviolet absorbance detection, electrospray ionisation, collision-induced dissociation and tandem mass spectrometry for the on-line characterization of polyphenols and methylxanthines in green coffee beans. Rapid Commun Mass Spectrom 23:363-383

12. Clifford MN (2003) Hierarchical scheme for LC-MS ${ }^{\mathrm{n}}$ identification of chlorogenic acids. J Agric Food Chem 51:2900-2911

13. Farah A, de Paulis T, Moreira DP, Trugo LC, Martin PR (2006) Chlorogenic acids and lactones in regular and water-decaffeinated arabica coffees. J Agric Food Chem 54:374-381

14. Iwai K, Kishimoto N, Kakino Y, Mochida K, Fujita T (2004) In vitro antioxidative effects and tyrosinase inhibitory activities of seven hydroxycinnamoyl derivatives in green coffee beans. $\mathrm{J}$ Agric Food Chem 52:4893-4898

15. Farah A, Monteiro MC, Calado V, Franca AS, Trugo LC (2006) Correlation between cup quality and chemical attributes of Brazilian coffee. Food Chem 98:373-380

16. Farah A, de Paulis T, Trugo LC, Martin PR (2005) Effect of roasting on the formation of chlorogenic acids lactones in coffee. J Agric Food Chem 53:1505-1513

17. Monteiro MC, Farah A (2012) Chlorogenic acids in Brazilian Coffea arabica cultivars from various consecutive crops. Food Chem 134:611-614

18. Campa C, Doulbeau S, Dussert S, Hamon S, Noirot M (2005) Qualitative relationship between caffeine and chlorogenic acid contents among wild Coffea species. Food Chem 93:135-139

19. DIN-10767 (1992) Analysis of coffee and coffee products: determination of chlorogenic acids content-HPLC method

20. Rakotomalala JJR (1992) Diversité biochimique des caféiers: analyse des acides hydroxycinnamiques, bases puriques et diterpènes glycosides. Particularités des caféiers sauvages de la region malgache (Mascarocoffea Chev.). Université Sciences et Techniques du Languedoc, Montpellier II, France, Montpellier, France, p 219

21. Bicchi CP, Binello AE, Pellegrino GM, Vanni AC (1995) Characterization of green and roasted coffees through the chlorogenic acid fraction by HPLC-UV and principal component analysis. J Agric Food Chem 43:1549-1555

22. Suárez-Quiroz ML, Alonso Campos A, Valerio Alfaro G, González-Ríos O, Villeneuve P, Figueroa-Espinoza MC (2014) Isolation of green coffee chlorogenic acids using activated carbon. J Food Compos Anal 33:55-58

23. Balyaya KJ, Clifford MN (1995) Individual chlorogenic acids and caffeine contents in commercial grades of wet and dry processed Indian green Robusta coffee. J Food Sci Technol Mys 32:104-108

24. Trugo LC, Macrae R (1984) A study of the effect of roasting on the chlorogenic acid composition of coffee using HPLC. Food Chem 15:219-227

25. Alonso-Salces RM, Serra F, Reniero F, Héberger K (2009) Botanical and geographical characterization of green coffee
(Coffea arabica and Coffea canephora): chemometric evaluation of phenolic and methylxanthine contents. J Agric Food Chem 57:4224-4235

26. Upadhyay R, Ramalakshmi K, Rao LJM (2012) Microwaveassisted extraction of chlorogenic acids from green coffee beans. Food Chem 130:184-188

27. Budryn G, Nebesny E, Podsędek A, Żyżelewicz D, Materska M, Jankowski S, Janda B (2009) Effect of different extraction methods on the recovery of chlorogenic acids, caffeine and Maillard reaction products in coffee beans. Eur Food Res Technol 228:913-922

28. Ky C-L, Noirot M, Hamon S (1997) Comparison of five purification methods for chlorogenic acids in green coffee beans (Coffea sp.). J Agric Food Chem 45:786-790

29. Perrone D, Farah A, Donangelo CM, de Paulis T, Martin PR (2008) Comprehensive analysis of major and minor chlorogenic acids and lactones in economically relevant Brazilian coffee cultivars. Food Chem 106:859-867

30. Kuhnert N, Jaiswal R, Eravuchira P, El-Abassy RM, Kammer B, Materny A (2011) Scope and limitations of principal component analysis of high resolution LC-TOF MS data: the analysis of the chlorogenic acid fraction in green coffee beans as a case study. Anal Methods 3:144-155

31. Risso EM, Péres RG, Amaya-Farfan J (2007) Determination of phenolic acids in coffee by micellar electrokinetic chromatography. Food Chem 105:1578-1582

32. Belay A, Gholap AV (2009) Characterization and determination of chlorogenic acids (CGA) in coffee beans by UV-Vis spectroscopy. Afr J Pure Appl Chem 3:234-240

33. Caprioli G, Cortese M, Odello L, Ricciutelli M, Sagratini G, Tomassoni G, Vittori S (2013) Importance of espresso coffee machine parameters on the extraction of chlorogenic acids in a certified Italian Espresso by using SPE-786 HPLC-DAD. J Food Res 2:55-64

34. Niseteo T, Komes D, Belščak-Cvitanović A, Horžić D, Budeč M (2012) Bioactive composition and antioxidant potential of different commonly consumed coffee brews affected by their preparation technique and milk addition. Food Chem 134:1870-1877

35. Vignoli JA, Viegas MC, Bassoli DG, de Benassi M (2014) Roasting process affects differently the bioactive compounds and the antioxidant activity of arabica and robusta coffees. Food Res Int 61:279-285

36. Rodrigues NP, Bragagnolo N (2013) Identification and quantification of bioactive compounds in coffee brews by HPLCDAD-MS ${ }^{n}$. J Food Compos Anal 32:105-115

37. Alves RC, Almeida IMC, Casal S, Oliveira MBPP (2010) Method development and validation for isoflavones quantification in coffee. Food Chem 122:914-919

38. Jaiswal R, Matei MF, Subedi P, Kuhnert N (2014) Does roasted coffee contain chlorogenic acid lactones or/and cinnamoylshikimate esters? Food Res Int 61:214-227

39. Kaiser N, Birkholz D, Colomban S, Navarini L, Engelhardt UH (2013) A new method for the preparative isolation of chlorogenic acid lactones from coffee and model roasts of 5-caffeoylquinic acid. J Agric Food Chem 61:6937-6941

40. de Araújo TA, Cardoso JC, Barbosa AM, Ferreira VS (2009) Influence of the surfactant bromide of cetyltrimetyl ammonium in the determination of chlorogenic acid in instant coffee and mate tea samples. Colloids Surf B 73:408-414

41. de Carvalho ML, Santhiago M, Peralta RA, Neves A, Micke GA, Vieira IC (2008) Determination of chlorogenic acid in coffee using a biomimetic sensor based on a new tetranuclear copper(II) complex. Talanta 77:394-399

42. Fernandes SC, Moccelini SK, Scheeren CW, Migowski P, Dupont J, Heller M, Vieira IC (2009) Biosensor for chlorogenic acid based on an ionic liquid containing iridium nanoparticles and polyphenol oxidase. Talanta 79:222-228 
43. Santos WJR, Santhiago M, Yoshida IVP, Kubota LT (2011) Novel electrochemical sensor for the selective recognition of chlorogenic acid. Anal Chim Acta 695:44-50

44. Yardım Y, Keskin E, Şentürk Z (2013) Voltammetric determination of mixtures of caffeine and chlorogenic acid in beverage samples using a boron-doped diamond electrode. Talanta 116:1010-1017

45. Ziyatdinova G, Aytuganova I, Nizamova A, Budnikov H (2013) Differential pulse voltammetric assay of coffee antioxidant capacity with MWNT-modified electrode. Food Anal Methods 68:132-139

46. Murkies AL, Wilcox G, Davis SR (1998) Phytoestrogens. J Clin Endocrinol Metab 83:297-303

47. Alves RC, Almeida IMC, Casal S, Oliveira MBPP (2010) Isoflavones in coffee: influence of species, roast degree, and brewing method. J Agric Food Chem 58:3002-3007

48. Mazur W, Fotsis T, Wahala K, Ojala S, Salakka A, Adlercreutz H (1996) Isotope dilution gas chromatographic-mass spectrometric method for the determination of isoflavonoids, coumestrol, and lignans in food samples. Anal Biochem 233:169-180

49. Thompson LU, Boucher BA, Liu Z, Cotterchio M, Kreiger N (2006) Phytoestrogen content of food consumed in Canada, including isoflavones, lignans and coumestan. Nutr Cancer 54:184-201

50. Kuhnle GG, Dell'Aquila C, Low Y-L, Kussmaul M, Bingham SA (2007) Extraction and quantification of phytoestrogens in food using automated SPE and LC/MS/MS. Anal Chem 79:9234-9239

51. Oomah BD, Hosseinian FS (2007) In: W. J. Hurst (Ed.), Methods of analysis for functional foods and nutraceuticals (2nd ed.). Phytoestrogens. Boca Raton, FL: Taylor and Francis Group LLC

52. Kuhnle GGC, Dell'Aquila C, Aspinall SM, Runswick SA, Mulligan AA, Bingham SA (2008) Phytoestrogen content of beverages, nuts, seeds, and oils. J Agric Food Chem 56:7311-7315

53. Gloess A, Schönbächler B, Klopprogge B, D`Ambrosio L, Chatelain K, Bongartz A, Strittmatter A, Rast M, Yeretzian C (2013) Comparison of nine common coffee extraction methods: instrumental and sensory analysis. Eur Food Res Technol 236:607-627

54. Hečimović I, Belščak-Cvitanović A, Horžić D, Komes D (2011) Comparative study of polyphenols and caffeine in different coffee varieties affected by the degree of roasting. Food Chem 129:991-1000

55. Carrillo JA, Benitez J (2000) Clinically significant pharmacokinetic interactions between dietary caffeine and medications. Clin Pharmacokinet 39:127-153

56. Ky C-L, Louarn J, Dussert S, Guyot B, Hamon S, Noirot M (2001) Caffeine, trigonelline, chlorogenic acids and sucrose diversity in wild Coffea arabica L. and C. canephora P. accessions. Food Chem 75:223-230

57. Bispo MS, Veloso MCC, Pinhero HLC, De Oliveira RFS, Reis JON, De Andrade JB (2002) Simultaneous determination of caffeine, theobromine, and theophylline by high-performance liquid chromatography. J Chromatogr Sci 40:45-48

58. Casal S, Beatriz Oliveira M, Ferreira MA (2000) HPLC/diodearray applied to the thermal degradation of trigonelline, nicotinic acid and caffeine in coffee. Food Chem 68:481-485

59. Perrone D, Donangelo CM, Farah A (2008) Fast simultaneous analysis of caffeine, trigonelline, nicotinic acid and sucrose in coffee by liquid chromatography-mass spectrometry. Food Chem 110:1030-1035

60. Rodrigues CI, Marta L, Maia R, Miranda M, Ribeirinho M, Máguas C (2007) Application of solid-phase extraction to brewed coffee caffeine and organic acid determination by UV/ HPLC. J Food Compos Anal 20:440-448
61. Meinhart AD, Schaper Bizzotto C, Ballus CA, Prado MA, Bruns RE, Teixeira Filho J, Teixeira Godoy H (2010) Optimisation of a CE method for caffeine analysis in decaffeinated coffee. Food Chem 120:1155-1161

62. Danhelova H, Hradecky J, Pronosilova S, Cajka T, Riddellova K, Vaclavik L, Hajslova J (2012) Rapid analysis of caffeine in various coffee samples employing direct analysis in real-time ionization-high-resolution mass spectrometry. Anal Bioanal Chem 403:2883-2889

63. Singh BR, Wechter MA, Hu Y, Lafontaine C (1998) Determination of caffeine content in coffee using Fourier transform infra-red spectroscopy in combination with attenuated total reflectance technique: a bioanalytical chemistry experiment for biochemists. Biochem Educ 26:243-247

64. Belay A, Ture K, Redi M, Asfaw A (2008) Measurement of caffeine in coffee beans with UV/vis spectrometer. Food Chem 108:310-315

65. Salinas-Vargas ME, Cañizares-Macías MP (2014) On-line solid-phase extraction using a $\mathrm{C}_{18}$ minicolumn coupled to a flow injection system for determination of caffeine in green and roasted coffee beans. Food Chem 147:182-188

66. Aklilu M, Tessema M, Redi-Abshiro M (2008) Indirect voltammetric determination of caffeine content in coffee using 1,4-benzoquinone modified carbon paste electrode. Talanta 76:742-746

67. Chuan D, Yan-Li W, Shao-Min S (2003) Study on the paper substrate room temperature phosphorescence of theobromine, caffeine and theophylline and analytical application. Spectrochim Acta, Part A 59:1469-1476

68. Mersal GAM (2012) Experimental and computational studies on the electrochemical oxidation of caffeine at pseudo carbon paste electrode and its voltammetric determination in different real samples. Food Anal Methods 5:520-529

69. Bicho NC, Leitao AE, Ramalho JC, Lidon FC (2011) Identification of chemical clusters discriminators of the roast degree in Arabica and Robusta coffee beans. Eur Food Res Technol 233:303-311

70. De Maria CAB, Trugo LC, Aquino FR, Moreira RFA, Alviano CS (1996) Composition of green coffee water-soluble fractions and identification of volatiles formed during roasting. Food Chem 55:203-207

71. de Oliveira AL, Ceuz PM, Eberlin MN, Cabral FA (2005) Brazilian roasted coffee oil obtained by mechanical expelling: compositional analysis by GC-MS. Cienc Tecnol Alimentos 25:677-682

72. Somoza V, Lindenmeier M, Wenzel E, Frank O, Erbersdobler HF, Hofmann T (2003) Activity-guided identification of a chemopreventive compound in coffee using in vitro and in vivo techniques. J Agric Food Chem 51:6861-6869

73. Boettler U, Sommerfeld K, Volz N, Pahlke G, Teller N, Somoza V, Lang R, Hofmann T, Marko D (2011) Coffee constituents as modulators of Nrf2 nuclear translocation and ARE (EpRE)dependent gene expression. J Nutr Biochem 22:426-440

74. Boettler U, Volz N, Pahlke G, Teller N, Kotyczka C, Somoza V, Stiebitz H, Bytof G, Lantz I, Lang R, Hofmann T, Marko D (2011) Coffees rich in chlorogenic acid or $N$-methylpyridinium induce chemopreventive phase II-enzymes via the Nrf2/ARE pathway in vitro and in vivo. Mol Nutr Food Res 55:S143-S153

75. Allred KF, Yackley KM, Vanamala J, Allred CD (2009) Trigonelline is a novel phytoestrogen in coffee beans. J Nutr 139:1833-1838

76. Liu H, Shao J, Li Q, Li Y, Yan HM, He L (2012) Determination of trigonelline, nicotinic acid, and caffeine in Yunnan Arabica coffee by microwave-assisted extraction and HPLC with two columns in series. J AOAC Int 95:1138-1141 
77. Lang R, Yagar EF, Wahl A, Beusch A, Dunkel A, Dieminger R, Eggers R, Bytof G, Stiebitz H, Lantz I, Hofmann T (2013) Quantitative studies on roast kinetics for bioactives in coffee. J Agric Food Chem 61:12123-12128

78. Charlton AJ, Farrington WHH, Bereton P (2002) Application of $1 \mathrm{H}$ NMR and multivariate statistics for screening complex mixtures: quality control and authenticity of instant coffee. J Agric Food Chem 50:3098-3103

79. Consonni R, Cagliani LR, Cogliati C (2012) NMR based geographical characterization of roasted coffee. Talanta 88:420-426

80. del Campo G, Berregi I, Caracena R, Zuriarrain J (2010) Quantitative determination of caffeine, formic acid, trigonelline and 5-(hydroxymethyl) furfural in soluble coffees by ${ }^{1} \mathrm{H}$ NMR spectrometry. Talanta 81:367-371

81. Cai L, Ma D, Zhang Y, Liu Z, Wang P (2012) The effect of coffee consumption on serum lipids: a meta-analysis of randomized controlled trials. Eur J Clin Nutr 66:872-877

82. Jee SH, He J, Appel LJ, Whelton PK, Suh I, Klag MJ (2001) Coffee consumption and serum lipids: a meta-analysis of randomized controlled clinical trials. Am J Epidemiol 153:353-362

83. Lee KA, Chae JI, Shim JH (2012) Natural diterpenes from coffee, cafestol and kahweol induce apoptosis through regulation of specificity protein 1 expression in human malignant pleuralmesothelioma. J Biomed Sci 19:1-10

84. Pacetti D, Boselli E, Balzano M, Frega NG (2012) Authentication of Italian Espresso coffee blends through the GC peak ratio between kahweol and 16-O-methylcafestol. Food Chem 135:1569-1574

85. Urgert R, van der Weg G, Kosmeijer-Schuil TG, van de Bovenkamp P, Hovenier R, Katan MB (1995) Levels of the cholesterol-elevating diterpenes cafestol and kahweol in various coffee brews. J Agric Food Chem 43:2167-2172

86. Chartier A, Beaumesnil M, Lopes de Oliveira A, Elfakir C, Bostyn S (2013) Optimization of the isolation and quantitation of kahweol and cafestol in green coffee oil. Talanta 117:102-111

87. Gross G, Jaccaud E, Huggett AC (1997) Analysis of the content of the diterpenes cafestol and kahweol in coffee brews. Food Chem Toxicol 35:547-554

88. Sridevi V, Giridhar P, Ravishankar GA (2011) Evaluation of roasting and brewing effect on antinutritional diterpenes-cafestol and kahweol in coffee. Glob J Med Res 11:1-7

89. Oigman SS, de Souza R, dos Santos Júnior HM, Hovell AMC, Hamerski L, Rezende CM (2012) Microwave-assisted methanolysis of green coffee oil. Food Chem 134:999-1004

90. Tsukui A, Santos Júnior HM, Oigman SS, De Souza ROMA, Bizzo HR, Rezende CM (2014) Microwave-assisted extraction of green coffee oil and quantification of diterpenes by HPLC. Food Chem 164:266-271

91. Barbosa HMA, de Melo MMR, Coimbra MA, Passos CP, Silva CM (2014) Optimization of the supercritical fluid coextraction of oil and diterpenes from spent coffee grounds using experimental design and response surface methodology. J Supercrit Fluids 85:165-172

92. Scharnhop H, Winterhalter P (2009) Isolation of coffee diterpenes by means of high-speed countercurrent chromatography. $\mathbf{J}$ Food Comp Anal 22:233-237

93. D'Amelio N, De Angelis E, Navarini L, Schievano E, Mammi S (2013) Green coffee oil analysis by high-resolution nuclear magnetic resonance spectroscopy. Talanta 110:118-127

94. De Roos B, vander Weg G, Grdert R, van de Bovenkamp P, Charrier A, Katan MB (1997) Levels of cafestol, kahweol and related diterpenoids in wild species of the coffee plant. J Agric Food Chem 45:3065-3069

95. Dias RCE, de Faria-Machado AF, Mercadante AZ, Bragagnolo N, Benassi MT (2014) Roasting process affects the profile of diterpenes in coffee. Eur Food Res Technol. doi:10.1007/ s00217-014-2293-x

96. Galli V, Barbas C (2004) Capillary electrophoresis for the analysis of short-chain organic acids in coffee. J Chromatogr A 1032:299-304

97. Rogers WJ, Michaux S, Bastin M, Bucheli P (1999) Changes to the content of sugars, sugar alcohols, myo-inositol, carboxylic acids and inorganic anions in developing grains from different varieties of Robusta (Coffea canephora) and Arabica (C. arabica) coffees. Plant Sci 149:115-123

98. Verardo G, Cecconi F, Geatti P, Giumanini AG (2002) New procedures for determination of acids in coffee extracts, and observations on the development of acidity upon ageing. Anal Bioanal Chem 374:879-885

99. Bähre F, Maier HG (1996) Electrophoretic clean-up of organic acids from coffee for the GC/MS analysis. Fresenius J Anal Chem 355:190-193

100. Quiroz MLS, Campos AA, Alfaro GV, R'ios OG, Villeneuve P, Figueroa-Espinoza M-C (2013) Isolation of green coffee chlorogenic acids using activated carbon. J Food Comp Anal. doi:10.1016/j.jfca.2013.10.005

101. Chu Y-F, Brown PH, Lyle BJ, Chen Y, Black RM, Williams CE, Cheng IH (2009) Roasted coffees high in lipophilic antioxidants and chlorogenic acid lactones are more neuroprotective than green coffees. J Agric Food Chem 57:9801-9808

102. Duarte GS, Pereira AA, Farah A (2010) Chlorogenic acids and other relevant compounds in Brazilian coffees processed by semi-dry and wet post-harvesting methods. Food Chem 118:851-855

103. Jaiswal R, Matei MF, Golon A, Witt M, Kuhnert N (2012) Understanding the fate of chlorogenic acids in coffee roasting using mass spectrometry based targeted and nontargeted analytical strategies. Food Funct 3:976-984

104. De Maria CAB, Trugo LC, Moreira RFA (1995) Simultaneous determination of total chlorogenic acid, trigonelline and caffeine in green coffee samples by high performance gel filtration chromatography. Food Chem 2:447-449 